\title{
Neisseria meningitidis in a primary school
}

\author{
K J CANN, ${ }^{*}$ T R ROGERS, ${ }^{*}$ D M JONES, $\dagger$ N D NOAH $\ddagger$ AND C BURNS $\uparrow$ \\ Department of Medical Microbiology* and Community Medicine, $\uparrow$ Charing Cross and Westminster Medical \\ School, London, the Public Health Laboratory, Withington Hospital, Manchester, $\dagger$ and the Public Health \\ Laboratory Service Communicable Diseases Surveillance Centre, Colindale, London $\ddagger$
}

SUMmARY A prospective study of the nasopharyngeal carriage of sulphonamide resistant Neisseria meningitidis, group B, type $15 \mathrm{P} 1.16$, was undertaken after a cluster of four cases of meningococcal infections had occurred, two of which were fatal, during a three year period among children attending an inner London primary school. Throughout the year of the study the overall carriage and acquisition rates of meningococci were less than $6 \%$ and $1 \%$, respectively, and were no different from those of control children of similar age and ethnic origin from another school. The outbreak strain was isolated from three children in the study school, however, but from none in the control school. A comparison of bactericidal activity in serum against the outbreak strain in children from selected classes in each school showed that there was no lack of bactericidal activity to this strain in the study school. The low prevalence of strain specific bactericidal activity in sera taken from classroom contacts of carriers, combined with the low carriage and acquisition rates, suggested a pattern of prolonged colonisation with infrequent transmission of the organism from child to child, and was consistent with the pattern of cases seen in the school.

Despite improvements in the diagnosis and treatment of meningococcal disease the mortalities of $7 \%$ for meningitis and $19 \%$ for septicaemia have not changed over the past 30 years. Group B strains have consistently been the most common cause of the disease in the United Kingdom, and serotype 15, which is often sulphonamide resistant, is now superseding type 2 as the most common strain. ${ }^{1}$ The epidemiology of meningococcal carriage has been intensively investigated in adults (originally military recruits ${ }^{2}$ ) but more recently in school and family populations. ${ }^{3-6}$ One of these surveys showed that childhood populations of low socioeconomic group who lived in densely populated areas had an increased risk of meningococcal disease. ${ }^{3}$

Our study was carried out because of an unusual sequence of four cases (which occurred over three years) in a primary school. One third of the school population was of Spanish or Portuguese origin, as were three of the four cases. Similarly high proportions of children of Iberian origin exist in several state schools in inner London but there was no evidence of an unusually high incidence of meningococcal infection in these or any other schools, or in the Iberian community generally. In both fatal cases the causative organism was confirmed as $N$ meningitidis, group $\mathrm{B}$, type $15 \mathrm{P} 1.16$, which is sulphonamide resistant; in the third case the organism was isolated only from a throat swab, and in the fourth case meningococcal antigen was detected in cerebrospinal fluid by counterimmunoelectrophoresis, but cultures were sterile (table 1).

This study aimed to find out why cases of meningococcal disease were occurring regularly in this school but not in others. There were two possible patterns of spread of the organism: either it was being transmitted rapidly with a short duration of carriage (a low case:carrier ratio); or it was being transmitted slowly with a prolonged duration of carriage (a high case:carrier ratio). To investigate these possibilities we looked at rates of meningococcal carriage and acquisition as well as the prevalence of strain specific bactericidal antibody activity in children at the study school and also those in a control school with a similar ethnic population but with no reported cases of meningitis. Selected environmental studies were also carried out in the two schools.

\section{Subjects and methods}

Both schools were in the inner London area and 
1114 Cann, Rogers, Jones, Noah, and Burns

Table 1 Details of four cases of meningitis

\begin{tabular}{|c|c|c|c|c|c|c|}
\hline $\begin{array}{l}\text { Case } \\
\text { No }\end{array}$ & $\begin{array}{l}\text { Date of } \\
\text { attack }\end{array}$ & $\begin{array}{l}\text { Age } \\
\text { (years) }\end{array}$ & Sex & $\begin{array}{l}\text { Laboratory } \\
\text { method }\end{array}$ & $\begin{array}{l}\text { Group and type of } \\
N \text { meningitidis }\end{array}$ & Outcome \\
\hline 1 & May 1981 & 6 & M & $\begin{array}{l}\text { Countercurrent } \\
\text { immunoelectrophoresis }\end{array}$ & Not known & Recovered \\
\hline 2 & December 1982 & 8 & M & Throat swab & B15 P1.16 & Recovered \\
\hline 3 & July 1983 & 11 & M & Blood culture & B15 P1.16 & Died \\
\hline 4 & May 1984 & 3 & $\mathrm{~F}$ & Blood culture & B15 P1.16 & Died \\
\hline
\end{tabular}

they both had a similarly high proportion of children of Iberian origin. The children studied were aged 3-12 years. Swabs were taken from children after parental consent had been obtained and from those members of staff who were agreeable in May and October 1985 and February 1986. In total, 1518 swabs were taken from children during the survey, 864 from the index school and 654 from the control school. Three separate cross sectional surveys were performed, although 255 children were swabbed in all three phases and 153 children were swabbed twice. Response rates in each swabbing exercise were high. In the immediate follow up after phases one and two a smaller additional sample of swabs and blood specimens was taken from classroom contacts of carriers of the outbreak strain as well as age matched children from the control school. This was done to detect carriers who might have been missed and to determine serum type specific bactericidal activity against the outbreak strain. Blood samples were also obtained from all group B meningococcal carriers and age matched controls.

Serial dilutions of heated serum were made in sterile Hanks's solution using sterile microtitre trays and 50 dropper pipettes. A suspension of an 18 hour homologous culture from blood agar of a group B15 P1.16 strain was made in nutrient broth to about Brown's tube 2. This suspension was then further diluted to about $1 / 30000$ to yield a growth of $20-50$ colonies a drop. Fresh guinea pig complement was diluted 1/10 and one volume of culture dilution and one volume of complement dilution were added to each serum dilution. A culture control well was also included containing one volume of culture, one volume of complement, and one volume of Hanks's solution. The tray was covered and incubated for one hour in air at $37^{\circ} \mathrm{C}$. One drop from each well was then transferred to a segment of a well dried blood agar plate and incubated overnight in carbon dioxide at $37^{\circ} \mathrm{C}$. The final titre is taken as $50 \%$ killing of growth in comparison with that of the control.

Swabs were taken from the posterior nasopharynx by community nurses who had received instruction on swabbing technique. The swabs were directly plated on to Thayer Martin agar containing vancomycin, colistin, and trimethoprim, and on to chocolate agar; these plates were immediately transported to the laboratory and incubated in carbon dioxide at $37^{\circ} \mathrm{C}$. The plates were examined at 24 and 48 hours. All colonies which resembled Neisseria spp were Gram stained and tested for oxidase production. A rapid test (ONPG) for the enzyme $\beta$ galactosidase was performed on all Gram negative oxidase positive cocci to exclude Neisseria lactamica, a common commensal of the nasopharynx in young children. Serum carbohydrate utilisation tests were then performed on all isolates negative by ONPG; those organisms utilising glucose and maltose alone were identified as $N$ meningitidis. All isolates of $N$ meningitidis were serogrouped and subsequentr serotyped by coagglutination.

We elected to give prophylaxis to all group meningococcal carriers while waiting for the results of typing, and arrangements were made with general practitioners to prescribe rifampicin $10 \mathrm{mg} / \mathrm{kg}$ twice daily for 48 hours. Household contacts of all group B carriers were swabbed and given prophylaxis if they were found to be carriers. Eradication of carriage was confirmed by swabbing 48 hours after completion of prophylaxis with rifampicin.

Environmental measurements in the two schools included recordings of temperature, relative humidity, and ventilation rate. Daily recordings were made in two locations (the school hall and one classroom) during July 1985.

The prevalence of meningococcal carriage in each phase was calculated as the total number of meningococci divided by the number of children swabbed. The meningococcal acquisition rate was calculated for the duration of the study as the number of newly acquired meningococci after at least one negative swab divided by the number of person months of observation.

The short duration of this survey, three swabbings at four monthly intervals, together with rifampicin, did not allow us to calculate the mean duration of meningococcal carriage.

The $\chi^{2}$ test with Yates's correction was used to calculate the significance of differences between the 
rates of carriage and acquisition and Fisher's exact test was used to calculate the significance of differences between the prevalence of type specific bactericidal activity in the two schools.

\section{Results}

The meningococcal carriage rates ranged from $3 \cdot 9-2 \cdot 4 \%$ in the study school and $5 \cdot 6-1 \cdot 8 \%$ in the control school and were not significantly different during any phase of the study $\left(\chi^{2}=0 \cdot 065 ; p>0 \cdot 05\right)$. The 14 group $\mathrm{B}$ meningococcal isolates were a heterogeneous collection of serotypes and type B15 P1.16 accounted for only three of these, all from children at the study school (table 2).

In the study and control schools there were 10 and 11 newly acquired strains of $N$ meningitidis, respectively, giving corresponding acquisition rates of $0.6 \%$ and $0.9 \%\left(\chi^{2}=0.89 ; p>0.05\right)$.

In phase one the outbreak strain was isolated from a boy in the same class $(F)$ as the brother of the most recent child to die (case 4, table 1). The brother had received rifampicin and had been shown to be carrying the organism at the time of his sister's death 12 months previously. Because of this, repeat swabs were obtained and blood specimens were taken from 15 of the 20 children in the class; one more carrier of a group B meningococcus of a different serotype was identified.

Only four of the children swabbed in class $\mathrm{F}$ had detectable strain specific bactericidal activity in their serum, one of whom was the carrier who also had the highest titre. Of the carriers of other group B meningococci, three had low titres against the B15 P1.16 strain but usually had the highest titre against their homologous strain. The children tested from the control school did not have detectable bactericidal activity against the outbreak strain.

In phase two, the outbreak organism was isolated from two children in different classes who were apparently not in contact with the carrier in phase one. Children in these two classes as well as in two age matched classes in the control school had further swabs and blood samples taken. These children were aged 9 to 10 years and 10 to 11 years; 39 of 52 had blood samples taken at the study school, and 32 of 56 at the control school (table 3). The proportion of children with type specific activity in the study school classes $(38 \%)$ was significantly higher than that in the control school $(9 \%)$ (Fisher's exact test,

Table 2 Meningococcal isolates from children in each phase of the study

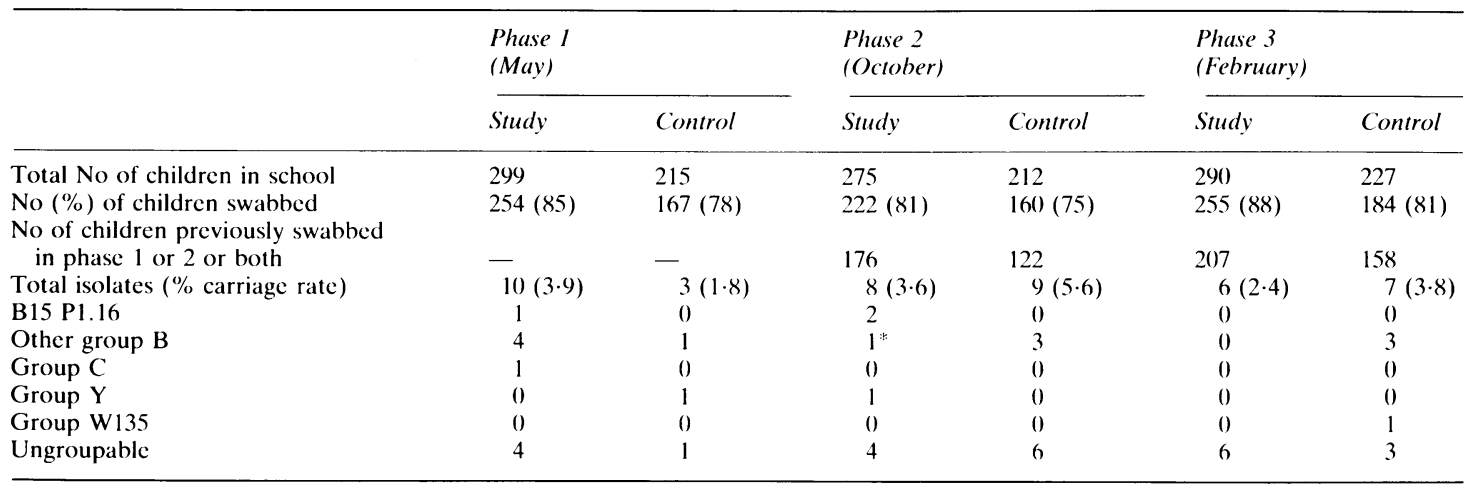

*This isolate also found in phase 1 due to failure of eradication of carriage by rifampicin.

Table 3 Sera obtained in phase 2 with bactericidal activity titre of $\geqslant 1 / 2$ against serotype BI5 PI.16

\begin{tabular}{|c|c|c|c|c|c|c|}
\hline \multirow{2}{*}{$\begin{array}{l}\text { Age } \\
\text { group } \\
\text { (years) }\end{array}$} & \multicolumn{3}{|c|}{ Study school } & \multicolumn{3}{|c|}{ Control school } \\
\hline & $\begin{array}{l}\text { No in } \\
\text { class }\end{array}$ & $\begin{array}{l}\text { No } \\
\text { sampled }\end{array}$ & $\begin{array}{l}\text { No }(\%) \text { with } \\
\text { activity }\end{array}$ & $\begin{array}{l}\text { No in } \\
\text { class }\end{array}$ & $\begin{array}{l}\text { No } \\
\text { sampled }\end{array}$ & $\begin{array}{l}\text { No }(\%) \text { with } \\
\text { activity }\end{array}$ \\
\hline $9-10$ & 23 & 21 & $10 \quad(43)$ & 30 & 12 & $3(23)$ \\
\hline $10-11$ & 29 & 20 & $5 \quad(31)$ & 26 & 20 & $0(0)$ \\
\hline Total & 52 & 41 & $15^{*}(38)$ & 56 & 32 & $3^{*}(9)$ \\
\hline
\end{tabular}

${ }^{*} \mathrm{p}=0 \cdot(0) 9$ (Fisher's exact test). 
$p=0.009)$. High titres of bactericidal activity were found in carriers of the outbreak strain; most of the other children with detectable activity had low titres, possibly related to cross reactions from carriage of other meningococcal strains. There were no isolates of the outbreak organism in phase three and no further blood testing was done.

None of the household contacts of the group B carriers was carrying the same meningococcal strain but the parents of one child were carrying a different meningococcal serotype. In one child the rifampicin failed to eradicate the organism; the strain was not resistant and eradication was achieved with a second course.

Between 50 and $80 \%$ of the school staff were swabbed in each phase; none of them was a carrier of the outbreak strain although one teacher carried a group $\mathrm{C}$ non-typable meningococcus throughout the survey period.

The environmental studies showed that the temperatures in the hall of the study school were consistently higher by $3 \cdot 5-4^{\circ} \mathrm{C}$ (the mean values for July were $19.7^{\circ} \mathrm{C}$ for the control school and $23.8^{\circ} \mathrm{C}$ for the study school). Although these measurements were only made during the one month, they showed a trend that might be continuous over the year. Ventilation studies suggested that the study school could overheat during periods of high occupancy and in hot calm weather.

\section{Discussion}

Since 1981 there has been an increasing incidence of group B type 15 meningococcal disease in England characterised by clusters of infection in particular communities. $^{7}$ A small but worrying sequence of cases in a primary school led to this controlled study.

We did not find any significant differences in rates of meningococcal carriage or acquisition between the two schools. Both rates were lower than has been reported in other surveys which, unlike this one, were performed during epidemics. ${ }^{3-6}$ The notable and significant difference between the two school populations, however, was that carriage of the B15 P1.16 strain persisted in children at the study school.

We established a pattern of slow transmission and prolonged duration of carriage by showing a low prevalence of the outbreak strain and a low level of type specific bactericidal activity among classroom contacts of carriers. We consistently found the highest titres of activity in the group B strain carriers rather than in the contacts, none of whom developed meningococcal disease in the time between swabbing and the administration of rifampicin. Although we do not known the length of carriage required for high concentrations of bactericidal activity to develop, these findings indicate that the emphasis should be on prophylaxis to eradicate carriage rather than on the treatment of the carriers to prevent invasive disease (as is being done in some Scandinavian countries). Recent studies using DNA fingerprinting techniques, in addition to conventional serogrouping and serotyping methods have shown that there is variation in phenotypic expression of the group and type of antigens within a strain. The application of this technique to our carrier strains, particularly the non-groupable ones, might provide more useful epidemiological information. 8

Classroom contacts of B15 P1.16 carriers with detectable bactericidal activity in serum were found in both control and study schools; the significantly higher proportion in classes of the study school can be partly attributed to the circulation of the outbreak strain as well as to the carriage of other closely related strains in these children. These findings show no evidence of inability to develop immunity to the outbreak strain among the children sampled.

The environmental studies showed that in the more modern building of the study school the temperatures were higher and the ventilation systems perhaps not adequate to cope during periods of overcrowding. The importance of this in the aetiology of the infections in the study school is not clear. Comparable environmental studies do not seem to have been undertaken in this country.

This study has shown that a prolonged sequence of cases of meningococcal infection may occur associated with low transmission and carriage rates and no disproportionate lack of specific immunity in the population. The four cases (two fatal) that occurred in the school over three years caused considerable concern among the parents, staff, and local health authority officials. Several meetings were held between medical staff and parents to discuss appropriate treatments or investigations, or both. It had been proposed that prophylaxis with rifampicin for all the study school children and staff should be started; this suggestion was resisted, and the decision subsequently justified by the low prevalence of the outbreak strain. The unusual policy of treating all group B meningococcus carriers with rifampicin was adopted primarily because of parental concern and also because of the inevitable delay in obtaining results of serotyping. We also aimed to reduce the number of opportunities for transmission of the outbreak organism within the community. There were always some children and staff not swabbed who might have included carriers and who could therefore recirculate the organism; in addition, the swabbing procedure itself would fail to 
identify all carriers. These limitations were impressed on the parents before the survey was undertaken.

We felt that it was ethically unjustifiable not to give prophylaxis to the carriers of the group B strain who were identified; although no further cases have occurred, we make no claim that the extensive swabbing combined with our policy of prophylaxis has been effective in terminating the outbreak. Because of the low carriage and transmission rates in the school, however, it may be that this intervention has reduced the likelihood of further cases. Our findings should stimulate a more extensive study with more frequent swabbing to obtain more information about duration of carriage.

We thank Mr C Wynne and Mr D Whybrew for technical assistance; Mrs J Eldridge for performing the serological studies; the Inner London Education Authority; the headmistresses of both schools and the children's parents for their cooperation; and the Building Systems Group of London Scientific Services for the environmental readings. Dr K Cann is supported by a grant from the North West Thames Regional Health Authority.

\section{References}

I Abbott JD, Jones DM, Painter MJ, Young SE. The epidemi- ology of meningococcal infections in England and Wales. 1912-1983. J Infect 1985;11:241-57.

2 McLeod-Griffiss J, Broud DB, Silver CA, Arnstein MS Immunoepidemiology of meningococcal disease in military recruits. I. A model of serogroup independency of epidemic potential as determined by serotyping. J Infect Dis 1977;136: $176-86$.

${ }^{3}$ De Wals P. Gilquin C. De Macyer S, et al. Longitudinal study of asymptomatic meningococcal carriage in two Belgian populations of school children. $J$ Infect 1983;6:147-56.

${ }^{4}$ Saez-Neito JA. Dominguez JR. Monton JL, et al. Carriage of Neisseria meningitidis and Neisseria lactamica in a school population during an epidemic period in Spain. J Hyg 1985;94: $279-88$.

5 Greenfield S. Sheehe PR, Feldman HA. Meningococcal carriage in a population of "normal" families. J Infect Dis 1971:123:67-73.

' Gold R, Goldschneider I, Lepow ML, Draper TF, Randolph M. Carriage of Neisseria meningitidis and Neisseria lactamica in infants and children. $J$ Infect Dis 1978:137:112-21.

${ }^{7}$ Cartwright KA, Stuart JM, Noah ND. An outbreak of meningococcal disease in Gloucestershire. Lancet 1986;ii:558-61.

${ }^{8}$ Kristiansen BE, Sorensen B, Bjorvatn B, et al. An outbreak of group B meningococcal Disease: Tracing the causative strain of Neisseria meningitidis by DNA fingerprinting. J Clin Microbiol 1986;23:764-7.

Correspondence to Dr KJ Cann. Department of Medical Microbiology, Charing Cross and Westminster Medical School, London SW1P 2AR

Received 3 June 1987 